\title{
Basilar-Type Migraine
}

National Cancer Institute

\section{Source}

National Cancer Institute. Basilar-Type Migraine. NCI Thesaurus. Code C117013.

A migraine disorder characterized by episodes that are preceded by focal neurological symptoms originating in the brainstem. 